\title{
EFFECT OF EXCESS CALCIUM INTAKE ON ABSORP- TION OF NITROGEN, FAT, PHOSPHORUS AND CALCIUM IN YOUNG RATS. THE USE OF ORGANIC CALCIUM SALT
}

\author{
Shiro Goto and Tsuneko SAwAmURA ${ }^{1}$ \\ Department of Nutrition, Tokyo University of Agriculture, Setagaya-ku, Tokyo
}

(Received May 1, 1973)

\begin{abstract}
This study was undertaken to determine the effects of the excess intake of organic calcium upon the absorption of other nutrients of foods taken at the same time.

Male albino rats of Wistar strain with initial body weight averaging $60 \mathrm{~g}$ were used. Calcium lactate was fed to the rats as the calcium source. The rats fed with an excess calcium diet show a loss of weight, increased fecal weight and decreased absorption and retention of nitrogen and phosphorus when compared with the control group. High dietary calcium to phosphorus ratio enhanced the excretion of combined fatty acid in feces. Excess levels of calcium and phosphorus in diet caused a functional kidney obstruction.
\end{abstract}

Previous studies by the authors made in the series of experiments have shown that high levels of dietary calcium to phosphorus ratio lead to a decrease in absorption of nitrogen and calcium. And moreover it leads to a decrease in retention of phosphorus in both young and growing rats $(1,2)$. Generally, inorganic calcium salts, especially calcium carbonate or calcium phosphate, are used as a calcium source in the experimental diet.

In previous literature, however, no mention has been made of the effect of organic calcium salts on nitrogen and phosphorus metabolism. Consequently, present study was undertaken to determine the effects of the excess intake of organic calcium upon the absorption of other nutrients.

\section{METHODS}

Fifteen male albino rats of Wistar strain with initial body weight averaging $60 \mathrm{~g}$ were used. After being fed the control ration for 2 days the rats were divided into three groups and were housed individually in metabolic cages. And then

\footnotetext{
1 五島孜郎，沢村経子
} 
they were fed respective ration for 30 days. Throughout the experimental period, the urine and feces of each rat were collected daily. During the entire feeding period the animals were given fresh food daily and the food consumption was measured. Distilled water was supplied ad libitum.

At the end of the experiment the animals were sacrificed and one side of femur and bilateral kidney were immediately removed.

The percentage composition of the diets and contents of calcium and phosphorus in the diets are shown in Table 1. Calcium and phosphorus levels were varied by the addition of calcium lactate and sodium phosphate, dibasic, dihydrate at the expense of corn starch.

Table 1. Composition of experimental diets, $\%$.

\begin{tabular}{|c|c|c|c|}
\hline & NN & EN & $\mathrm{EE}$ \\
\hline Casein, Milk & 18.0 & 18.0 & 18.0 \\
\hline Starch, Corn & 68.2 & 56.7 & 48.0 \\
\hline Oil, Corn & 5.0 & 5.0 & 5.0 \\
\hline Vitamin mix. $^{\mathrm{a}}$ & 1.0 & 1.0 & 1.0 \\
\hline Mineral mix. ${ }^{b}$ & 2.9 & 2.9 & 2.9 \\
\hline Ca-Lactate & 3.9 & 15.4 & 15.4 \\
\hline $\mathrm{Na}_{2} \mathrm{HPO}_{4} 2 \mathrm{H}_{2} \mathrm{O}$ & 1.0 & 1.0 & 9.7 \\
\hline Total & 100.0 & 100.0 & 100.0 \\
\hline $\mathrm{Ca}$ & 0.54 & 2.00 & 2.00 \\
\hline $\mathbf{P}$ & 0.50 & 0.50 & 2.00 \\
\hline $\mathrm{Ca} / \mathrm{P}$ & 1 & 4 & 1 \\
\hline
\end{tabular}

$\mathrm{NN}$ : normal $\mathrm{Ca}$, normal $\mathrm{P}$ diet. $\mathrm{EN}$ : excess $\mathrm{Ca}$, normal $\mathrm{P}$ diet. $\mathrm{EE}$ : excess $\mathrm{Ca}$, excess $P$ diet.

a One gram of this mixture contain (in milligrams): thiamin nitrate 1.0, riboflavin 1.5, niacin amide 10.0 , pyridoxine hydrochloride 1.0 , folic acid 0.15 , ascorbic acid 37.5 , calcium pantothenate 2.5 , vitamin $\mathrm{K} 0.2 \alpha$-tocopherol 1.0, vitamin $\mathrm{B}_{12} 1 \gamma$, vitamin $\mathrm{A}$ $2500 \mathrm{IU}$, vitamin D $200 \mathrm{IU}$ and contain choline chloride $100 \mathrm{mg}$.

${ }^{b}$ According to A. E. Haper (J. Nutr., 68, 405 (1959)), but $\mathrm{CaCO}_{3}$ was excepted.

Diet and excreta were analyzed for calcium, phosphorus, nitrogen and fat. Calcium analysis were made by EDTA titration (3), phosphorus analysis by GoMORI's method (4) after ashing at $550^{\circ} \mathrm{C}$, nitrogen analysis by micro-Kjeldahl method (5) and fat analysis was determined by Soxlhet's extract method (6). The determination of combined fatty acid in feces was made by TELFER's method (7).

Since the rats fed with EE (excess $\mathrm{Ca}$, excess $\mathrm{P}$ ) diet died from 12 th to 15 th day after the beginning of the experiment, most of the data are presented in two groups, namely, mean values of 10 days and 30 days, except the data of EE group. 


\section{RESULTS}

Food intake and average weight gain were lower in the excess-calcium-fed groups than in the control group ( $\mathrm{NN}$ : normal $\mathrm{Ca}$, normal $\mathbf{P}$ diet) and especially, weight lost in the EE group was extreme, as indicate in Table 2.

The fecal weight was very high in the excess-calcium-fed groups as compared with the NN group.

Table 2. Average weight gain, food intake and fecal weight.

\begin{tabular}{ccccccc}
\hline $\begin{array}{l}\text { Exptl. } \\
\text { period } \\
\text { (days) }\end{array}$ & Group & $\begin{array}{c}\text { Starting wt. } \\
(\mathrm{g})\end{array}$ & $\begin{array}{c}\text { Final wt. } \\
(\mathrm{g})\end{array}$ & $\begin{array}{c}\text { Av. daily } \\
\text { wt. gain(g) }\end{array}$ & $\begin{array}{c}\text { Av. daily } \\
\text { food } \\
\text { intake (g) }\end{array}$ & $\begin{array}{l}\text { Av. daily } \\
\text { fecal wt. (g) }\end{array}$ \\
\hline & NN & $60.8 \pm 1.0^{\mathrm{a}}$ & $99.6 \pm 3.6$ & $3.9 \pm 0.4$ & $8.6 \pm 0.4$ & $0.15 \pm 0.01$ \\
10 & EN & $60.0 \pm 1.8$ & $74.8 \pm 3.7$ & $1.5 \pm 0.4$ & $6.5 \pm 0.4$ & $0.39 \pm 0.06$ \\
& EE & $60.8 \pm 1.3$ & $65.2 \pm 4.9$ & $0.4 \pm 0.4$ & $5.5 \pm 0.4$ & $0.38 \pm 0.04$ \\
\hline \multirow{2}{*}{30} & NN & $60.8 \pm 1.0$ & $194.4 \pm 4.7$ & $4.5 \pm 0.1$ & $12.0 \pm 0.3$ & $0.26 \pm 0.06$ \\
& EN & $60.0 \pm 1.8$ & $133.8 \pm 11.2$ & $2.5 \pm 0.4$ & $8.3 \pm 0.5$ & $0.57 \pm 0.09$ \\
\hline
\end{tabular}

a Mean \pm SE.

Table 3. Fat balance with different levels of $\mathrm{Ca}$ and $\mathrm{P}$ intake.

\begin{tabular}{|c|c|c|c|c|c|c|}
\hline \multirow{2}{*}{$\begin{array}{l}\text { Exptl. } \\
\text { period } \\
\text { (days) }\end{array}$} & \multirow[b]{2}{*}{ Group } & \multirow{2}{*}{$\begin{array}{l}\text { Intake } \\
\text { (mg/day) }\end{array}$} & \multicolumn{4}{|c|}{ Fecal excretion } \\
\hline & & & $\begin{array}{c}\text { Neutral fat } \\
\text { (mg/day) }\end{array}$ & $\begin{array}{l}\text { Soap fat } \\
\text { (mg/day) }\end{array}$ & $\begin{array}{l}\text { Total lipid } \\
\text { (mg/day) }\end{array}$ & $\begin{array}{c}\text { Absorption } \\
(\%)\end{array}$ \\
\hline \multirow{3}{*}{10} & $\mathrm{NN}$ & $446.2 \pm 22.8^{a}$ & $25.1 \pm 3.2$ & $2.7 \pm 0.7$ & $27.8 \pm 3.4$ & $93.7 \pm 0.6$ \\
\hline & $\mathrm{EN}$ & $335.9 \pm 18.5$ & $20.1 \pm 1.5$ & $19.5 \pm 2.2$ & $39.7 \pm 3.5$ & $88.3 \pm 0.6$ \\
\hline & $\mathrm{EE}$ & $286.0 \pm 20.9$ & $12.1 \pm 1.8$ & $7.2 \pm 0.8$ & $19.3 \pm 2.2$ & $93.1 \pm 1.0$ \\
\hline \multirow[t]{2}{*}{30} & $\mathrm{NN}$ & $622.6 \pm 15.0$ & $31.8 \pm 3.9$ & $4.3 \pm 1.8$ & $36.1 \pm 4.2$ & $94.1 \pm 0.4$ \\
\hline & EN & $430.9 \pm 27.7$ & $28.0 \pm 6.2$ & $25.0 \pm 3.6$ & $53.0 \pm 9.8$ & $87.5 \pm 0.5$ \\
\hline
\end{tabular}

a Mean $\pm \mathrm{SE}$.

Table 3 shows that the high dietary calcium to phosphorus ratio leads to a high excretion of combined fatty acid and depresses the absorption of lipid. Table 4 summarizes the effect of excess calcium on the metabolism of nitrogen, phosphorus and calcium.

The rate of absorption and retention of nitrogen in NN group exhibited the highest value compared with the other groups.

There is no difference between EN (excess $\mathrm{Ca}$, normal $\mathrm{P}$ diet) and EE group in absorption rate of nitrogen but net retention of nitrogen decreased significantly in EE group. Urinary excretion of nitrogen apparently increased in EE group. In regard to phosphorus metabolism, NN group exhibited the highest absorption and retention rate of phosphorus among the three groups but the net absorption 
Table 4. Balance test of nitrogen, phosphorus and calcium. (All figures indicate \% of intake)

\begin{tabular}{|c|c|c|c|c|c|c|}
\hline & $\begin{array}{l}\text { Exptl. } \\
\text { period } \\
\text { (days) }\end{array}$ & Group & $\begin{array}{c}\text { Intake } \\
\text { (mg/day) }\end{array}$ & Absorption & $\begin{array}{l}\text { Urinary } \\
\text { excretion }\end{array}$ & Retention \\
\hline \multirow{5}{*}{$\mathrm{N}$} & \multirow{3}{*}{10} & NN & $210.9 \pm 10.7^{\mathrm{a}}$ & $95.8 \pm 0.4$ & $39.9 \pm 2.8$ & $55.8 \pm 2.4$ \\
\hline & & $\mathrm{EN}$ & $158.7 \pm 8.7$ & $86.4 \pm 1.6$ & $48.1 \pm 4.5$ & $38.3 \pm 1.0$ \\
\hline & & $\mathrm{EE}$ & $135.1 \pm 7.1$ & $89.2 \pm 1.4$ & $66.6 \pm 6.2$ & $22.6 \pm 6.6$ \\
\hline & \multirow[t]{2}{*}{30} & $\mathrm{NN}$ & $294.2 \pm 7.3$ & $94.7 \pm 0.3$ & $38.9 \pm 1.2$ & $55.8 \pm 0.9$ \\
\hline & & $\mathrm{EN}$ & $203.4 \pm 12.8$ & $89.5 \pm 0.4$ & $40.0 \pm 1.9$ & $49.4 \pm 2.0$ \\
\hline \multirow{5}{*}{$\mathbf{P}$} & \multirow{3}{*}{10} & $\mathrm{NN}$ & $42.9 \pm 2.2$ & $83.3 \pm 1.3$ & $34.0 \pm 2.9$ & $49.3 \pm 3.7$ \\
\hline & & EN & $32.3 \pm 1.8$ & $34.9 \pm 4.0$ & $5.5 \pm 1.3$ & $29.4 \pm 3.6$ \\
\hline & & $\mathrm{EE}$ & $110.0 \pm 8.0$ & $63.5 \pm 6.3$ & $34.0 \pm 2.6$ & $29.5 \pm 5.3$ \\
\hline & \multirow[t]{2}{*}{30} & $\mathrm{NN}$ & $60.0 \pm 1.5$ & $76.9 \pm 0.8$ & $19.3 \pm 1.0$ & $57.6 \pm 1.4$ \\
\hline & & EN & $41.4 \pm 2.6$ & $26.3 \pm 1.3$ & $3.6 \pm 0.9$ & $22.0 \pm 2.9$ \\
\hline \multirow{5}{*}{$\mathrm{Ca}$} & \multirow{3}{*}{10} & $\mathrm{NN}$ & $46.7 \pm 2.4$ & $74.0 \pm 2.0$ & $2.8 \pm 0.2$ & $71.2 \pm 2.1$ \\
\hline & & EN & $130.0 \pm 6.7$ & $43.7 \pm 1.9$ & $12.1 \pm 0.7$ & $31.6 \pm 2.5$ \\
\hline & & $\mathrm{EE}$ & $114.0 \pm 9.0$ & $38.3 \pm 7.8$ & $1.4 \pm 0.2$ & $36.9 \pm 7.9$ \\
\hline & \multirow[t]{2}{*}{30} & $\mathrm{NN}$ & $65.2 \pm 1.5$ & $62.8 \pm 1.4$ & $2.6 \pm 0.2$ & $60.2 \pm 1.4$ \\
\hline & & $\mathrm{EN}$ & $165.6 \pm 6.6$ & $32.6 \pm 3.3$ & $7.3 \pm 0.3$ & $25.2 \pm 3.2$ \\
\hline
\end{tabular}

a Mean $\pm \mathrm{SE}$.

Table 5. Concentration of $\mathrm{Ca}$ and $\mathrm{P}$ in femur and kidney.

\begin{tabular}{|c|c|c|c|c|c|c|}
\hline & Group & $\begin{array}{c}\text { Fat free } \\
\text { dry wt. (g) }\end{array}$ & P (mg) & $\mathrm{Ca}$ (mg) & $\mathrm{Ca} /$ & \\
\hline \multirow{3}{*}{ Femur } & $\mathrm{NN}$ & $0.24 \pm 0.01^{\mathrm{a}}$ & $25.9 \pm 0.5$ & $58.4 \pm 0.4$ & 2.3 & $*$ \\
\hline & $\mathrm{EN}$ & $0.19 \pm 0.01$ & $21.0 \pm 1.3$ & $49.5 \pm 2.6$ & 2.4 & $*$ \\
\hline & $\mathrm{EE}$ & $0.09 \pm 0.01$ & $9.1 \pm 0.9$ & $22.4 \pm 2.2$ & 2.5 & $* *$ \\
\hline \multirow{4}{*}{ Kidney } & \multicolumn{3}{|c|}{ dry wt. (g) } & & & \\
\hline & NN & $0.35 \pm 0.01$ & $3.3 \pm 0.04$ & $1.0 \pm 0.1$ & 0.3 & $*$ \\
\hline & $\mathrm{EN}$ & $0.24 \pm 0.02$ & $2.6 \pm 0.22$ & $0.9 \pm 0.1$ & 0.4 & $*$ \\
\hline & $\mathrm{EE}$ & $0.66 \pm 0.11$ & $54.5 \pm 5.40$ & $98.4 \pm 10.7$ & 1.8 & ** \\
\hline
\end{tabular}

a Mean \pm SE.

* Analytical value after 30-day experimental period.

** Analytical value after 10-day experimental period.

and retention of phosphorus were higher in EE group as compared with the other groups of the 10-day experimental period.

Similarly, for phosphorus metabolism, NN group showed higher calcium absorption and retention rate than EN or EE group. However, since EN group exhibited higher net absorption of calcium and also indicated higher urinary excretion of calcium, NN and EN group showed essentially an identical retention 
in the 30-day experimental period.

Mineral contents in femur and kidney are shown in Table 5. Since EE group died early, this group could not be compared with other groups.

It is demonstrated in the table that calcium and phosphorus contents in femur of NN group were higher than those of EN group.

These results are similar to the results of calcium and phosphorus retention in the balance study.

The kidney of EE group showed high dry matter weight and phosphorus and calcium contents were extremely high in comparison to the other groups. It seems that this phenomenon accelerated the death of rats fed the EE diet.

\section{DISCUSSION}

Excess supply of calcium lactate caused a fall in food intake and weight gain and moreover excess calcium diet caused an increase in the quantity of feces and a decrease in net absorption of nitrogen. Excess calcium and excess phosphorus diet (EE) caused a decrease in the retention of nitrogen which is accompanied by increased urinary excretion of nitrogen.

These results are in agreement with our previous studies $(1,2)$ using calcium carbonate as calcium source in diet.

It follows that the excess calcium supply exhibits similar results to one another regardless of calcium form.

Excess calcium in the diet decreased the absorption of fat and especially, high levels of dietary calcium to phosphorus ratio led to a depression in absorption of fat.

Furthermore, we observed that dietary high ratio of calcium to phosphorus caused an extremely high excretion of combined fatty acid.

The ingested fat may be hydrolyzed to free fatty acids, forming insoluble calcium soaps which are excreted in feces.

It has been demonstrated in rats that excess calcium in the diet lowers absorption of fats $(8-10)$. There have scarcely been any studies on the possible effect of the level of dietary phosphorus upon the utilization of fat. TADAYYON et al. (11) reported that when either one of calcium and phosphorus intake was high and the other intake was low, the absorption of the long chain saturated triglicerides was decreased without any effect on unsaturated triglycerides.

Our results however, indicated that a high calcium intake caused a decrease in the absorption of highly unsaturated fat (corn oil).

This phenomenon may supposedly be due to the chemical form of calcium compound used in the experiment, while we have no clear-cut evidence for it at present.

With respect to phosphorus metabolism, the EE diet group indicated an increase in absorption, retention and urinary excretion of phosphorus, as com- 
pared with the other groups. SCHRYVER et al. (12) reported that phosphorus retention was greater when ponies were fed on a high phosphorus diet, despite an increased urinary and fecal excretion of phosphorus.

In our studies, the EE group enhanced the retention of phosphorus more than the other groups. It seems that the EE diet caused the functional obstruction of kidney and this phenomenon brought on the death of animals.

The results of calcium metabolism obtained in our study are in agreement with the abundant data (13-15) in experiments reported on the influence of increasing intakes of dietary calcium upon the utilization of calcium. Thus, high levels of calcium increase the net retention of calcium by the animal but result in a marked reduction in efficiency.

\section{REFERENCES}

1) Sawamura, T. and Goto, S., J. Jap. Soc. Food and Nutr. (in Japanese), 25, 597 (1972).

2) Goto, S. and Sawamura, T., Nutr. Reports International, 7, 103 (1973).

3) Ueno, K., Chelate Titration, Nanko-do, Tokyo (1961).

4) Gomori, G., J. Lab. Clin. Med., 27, 955 (1942).

5) Mrtsuda, H., Experimental Nutritional Chemistry, Izumi-shobo, Kyoto (1964).

6) Mitsuda, H., Experimental Nutritional Chemistry, Izumi-shobo, Kyoto (1964).

7) Telfer, S. V., Quart. P. J. Med., 16, 45 (1922); J. Jap. Soc. Food and Nutr. (in Japanese), 7, 253 (1955).

8) Fleischman, A. I., Yacowitz, H., Hayton, T., and Bierenbaum, M. L., J. Nutr., 88, 255 (1966).

9) Fleischman, A. I., Yacowitz, H., Hayton, T., and Bierenbaum, M. L., J. Nutr., 91, 151, (1967).

10) Yacowitz, H., Fleischman, A. I., Amsden, R. T., and Bierendaum, M. L., J. Nutr., 92, 389 (1967).

11) TAdAYYon, B. and LutwaK, L., J. Nutr., 97, 246 (1969).

12) Schryver, H. F., Hintz, H. F., and Craig, P. H., J. Nutr., 101, 1257 (1971).

13) Hansard, S. L. and Plumlee, M. P., J. Nutr., 54, 17 (1954).

14) Irving, J. T., Calcium Metabolism, John Wiley \& Sons, New York (1957).

15) MaLm, O. J., in R. H. Wasserman (Editor), The Transfer of $\mathrm{Ca}$ and $\mathrm{Sr}$ Across Biological Membranes, Academic Press, New York, p. 143 (1963). 